\title{
INNOVATIVE TEST RIG FOR JET FUELS THERMAL STABILITY TESTING \\ INNOWACYJNE STANOWISKO BADAWCZE DO OKREŚLANIA STABILNOŚCI TERMICZNEJ PALIW LOTNICZYCH
}

\author{
Jarosław Sarnecki \\ Instytut Techniczny Wojsk Lotniczych, Warszawa \\ e-mail: jaroslaw.sarnecki@itwl.pl
}

\begin{abstract}
The article deals with laboratory test method for jet fuels thermal stability testing. Author described the reasons that led to test rig preparation, its construction and operation principles. Innovative test rig for jet fuels thermal stability testing enables research in wide thermal conditions and different pressures. Testing capabilities and advantages compared with currently used standard test method of jet fuels thermal stability testing according to ASTM D3241 have been also presented.
\end{abstract}

Keywords: jet engine, jet fuel, thermal stability, test rig

Streszczenie: Artykut porusza tematyke badania $w$ warunkach laboratoryjnych stabilności termicznej paliw lotniczych. Opisano przyczyny budowy stanowiska, zatożenia, przedstawiono konstrukcje oraz działanie niestandardowego innowacyjnego stanowiska laboratoryjnego umożliwiającego badanie stabilności termicznej paliw lotniczych $w$ szerokim zakresie narażen termicznych $i$ różnych wartościach ciśnienia w układzie paliwowym. Przedstawiono możliwości badawcze oraz zalety stanowiska $w$ porównaniu $z$ obecnie stosowana znormalizowana metoda badania stabilności termicznej paliw lotniczych wg ASTM D3241.

Stowa kluczowe: silnik turbinowy, paliwo lotnicze, stabilność termiczna, stanowisko badawcze 
Innovative test rig for jet fuels thermal stability testing

Innowacyjne stanowisko badawcze do określania stabilności termicznej...

\section{Wstęp}

W wyniku działania zmiennych i wysokich temperatur na paliwo znajdujące się w układzie paliwowym statku powietrznego następuje degradacja termiczna paliwa, co w eksploatacji objawia się m.in. poprzez tworzenie nagarów w instalacji paliwowej, a zwłaszcza na wtryskiwaczach. Jest to niebezpieczne zjawisko występujące dość często w eksploatacji silników lotniczych - jego efektem jest zaburzenie wtrysku paliwa do komory spalania i przebiegu procesu spalania, a w eksploatacji skutkuje uszkodzeniami gorących części silników, np.:

- uszkodzeniami termicznymi rur żarowych i komór spalania w wyniku zaburzenia stożka wtrysku i nierównomiernego rozkładu pola temperatur;

- uszkodzeniami kierownic i łopatek turbin w wyniku uderzeń twardymi cząstkami nagaru odrywającymi się od wtryskiwaczy w trakcie eksploatacji;

- uszkodzeniami termicznymi (nadpaleniami, przepaleniami) kierownic turbin w wyniku przesunięcia czoła płomienia i zmiany rozkładu pól temperatur.

Jako podstawowa i powszechnie uznana metoda badania stabilności termicznej paliw lotniczych w dokumentach definiujących wymagania jakościowe dla paliw lotniczych (AFQRJOS [7], ASTM D1655 [8], ASTM D7566 [9]) występuje metoda ASTM D3241 wykorzystująca aparat JFTOT. Jednak światowe wyniki badań $[1,2]$ wskazują, iż wyniki uzyskiwane tą metodą nie korelują z wynikami badań stanowiskowych symulujących pracę układów paliwowych statków powietrznych i nie odzwierciedlają rzeczywistej skłonności paliwa lotniczego do degradacji w wysokich temperaturach. Przyczynami tego są [1, 2]:

- krótki czas trwania badania $(2,5 \mathrm{~h})$, powodujący, iż na uzyskany wynik ma wpływ obecność w paliwie deaktywatora metali (MDA);

- laminarny przepływ paliwa $\mathrm{w}$ aparacie JFTOT (w układach paliwowych statków powietrznych przepływ paliwa jest turbulentny);

- subiektywna ocena wzrokowa osadów powstałych na rurce testowej;

- wstępne filtrowanie paliwa przez sączek o średnicy porów $0,45 \mu \mathrm{m}$, tj. o rząd wielkości dokładniejsze oczyszczenie niż w układzie paliwowym statku powietrznego $(10-40 \mu \mathrm{m})$, a w konsekwencji usunięcie zanieczyszczeń mogących w sposób znaczący wpływać na tworzenie osadów w procesie degradacji termicznej;

- nie uwzględnienie składu chemicznego warstw wierzchnich elementów konstrukcyjnych układu paliwowego (rurka testowa w metodzie JFTOT, na której podczas badania laboratoryjnego osadzają się produkty degradacji termicznej paliwa lotniczego, jest wykonana $\mathrm{z}$ aluminium, natomiast elementy układów paliwowych statków powietrznych są wykonane ze stali nierdzewnej);

- nie uwzględnienie ciśnienia panującego w układach paliwowych statków powietrznych (w badaniu laboratoryjnym paliwo jest przetłaczane pod ciśnieniem 3,45 $\mathrm{MPa}$, natomiast $\mathrm{w}$ układach paliwowych ciśnienie jest znacznie wyższe, i osiąga wartość nawet ok. 7,0 MPa); 
- nie uwzględnienie $\mathrm{w}$ metodzie JFTOT temperatur $\mathrm{z}$ zakresu pirolitycznego (temperatura badania wynosi $260^{\circ} \mathrm{C}$, natomiast w układzie paliwowym paliwo ma kontakt z elementami o temperaturze przekraczającej $400^{\circ} \mathrm{C}$ ).

Powyższe czynniki powodują, iż prowadząc badania nad stabilnością termiczną konieczne jest podejście niestandardowe i wykorzystanie indywidualnie konstruowanych stanowisk badawczych. Na konieczność niestandardowego podejścia do tematyki degradacji termicznej paliw lotniczych wskazują także wyniki prac prowadzonych w ośrodkach badawczych na świecie [1-5].

\section{Założenia do budowy stanowiska badawczego}

Aktualnie powszechnie stosowaną metodą do badania stabilności termicznej paliw do turbinowych silników lotniczych jest metoda wg ASTM D3241 [6], wykorzystująca aparat JFTOT (Jet Fuel Thermal Oxidation Tester). Zasada metody opiera się na przepływie oczyszczonego ( $\mathrm{z}$ dokładnością $0,45 \mu \mathrm{m}$ ) paliwa lotniczego (prędkość przepływu $3 \mathrm{ml} / \mathrm{min}$ ) przez rurę grzewczą pod ciśnieniem $3,45 \mathrm{MPa}$, a następnie przez filtr o średnicy porów $17 \mu \mathrm{m}$ wykonany ze stali nierdzewnej, w którym wychwytywane są produkty rozkładu paliwa. Badanie trwa ok. 2,5 godzin, badana jest próbka o objętości $600 \mathrm{ml}$ (ok. $450 \mathrm{ml}$ jest przepompowywane $\mathrm{w}$ trakcie testu) $\mathrm{w}$ temperaturze $260^{\circ} \mathrm{C}$. Badane paliwo jest oceniane za pomocą dwóch wskaźników:

- spadek ciśnienia na filtrze;

- osady tworzące się na rurce testowej - ocena wzrokowa.

Uwzględniając wymienione wcześniej $\mathrm{w}$ artykule wady metody znormalizowanej założono, iż opracowywane stanowisko powinno pozwalać na wyeliminowanie ww. negatywnych czynników (krótki czas badania, ocena jakościowa, zdefiniowana średnica wyłapywania osadów tworzących się w paliwie), a także umożliwiać:

- ilościową ocenę osadów powstających w paliwie lotniczym w wyniku oddziaływania wysokich temperatur, a tym samym ocenę badanych paliw wyłącznie na podstawie parametru obiektywnego;

- sterowanie wartościami temperatur oddziałujących na paliwo lotnicze;

- śledzenie procesu tworzenia $\mathrm{w}$ paliwie produktów termicznego rozkładu w zależności od czasu oraz działających temperatur.

Aktualnie wyróżnia się dwa mechanizmy prowadzące do rozkładu termicznego paliwa lotniczego i tworzenia osadów:

- gdy paliwo osiąga wysoką temperaturę (pow. $400^{\circ} \mathrm{C}$ ), następuje kraking termiczny (piroliza);

- w temperaturach $150-350^{\circ} \mathrm{C}$ paliwo reaguje $\mathrm{z}$ nierozpuszczonym tlenem, tworząc wolne rodniki, które następnie mogą wchodzić w reakcje 
Innovative test rig for jet fuels thermal stability testing Innowacyjne stanowisko badawcze do określania stabilności termicznej...

z cząsteczkami zawierającymi cząsteczki azotu, siarki i tlenu. Powstające substancje są odpowiedzialne za tworzenie żywic i osadów.

Do budowy stanowiska przyjęto zatem założenie, iż będzie ono wykorzystywane w badaniu mechanizmów i kinetyki reakcji rozkładu termicznego paliwa w temperaturach do $500^{\circ} \mathrm{C}$.

\section{Schemat i opis działania stanowiska badawczego}

Ogólny schemat blokowy stanowiska badawczego przedstawiono na rys. 1, a schemat funkcjonalny na rys. 2

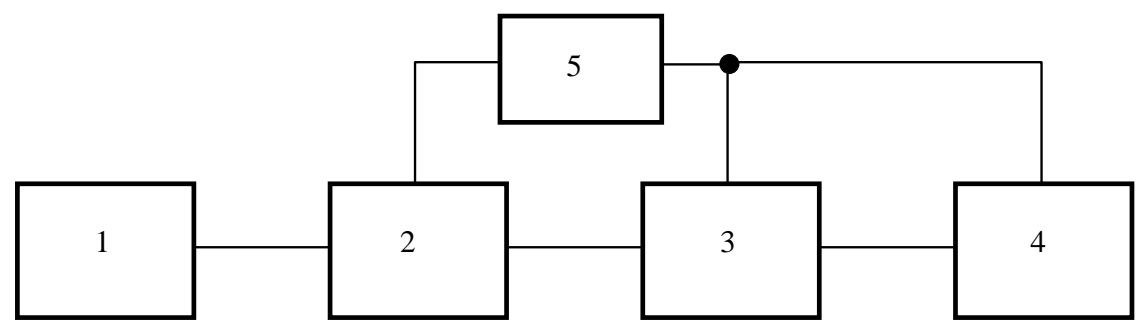

Rys. 1. Schemat blokowy stanowiska: 1- blok filtracyjno-ttoczacy; 2 - blok grzewczy; 3 - blok chłodzacy; 4 - blok końcowy; 5 - blok rejestrujacy

Zadaniem bloku filtracyjno-tłoczącego (1) jest zapewnienie właściwej czystości paliwa, które dostaję się na pompę tłoczącą oraz umożliwienie przepływu czynnika roboczego w układzie badawczym z zadaną prędkością.

$\mathrm{W}$ bloku grzewczym (2) podgrzewane jest przepływające w instalacji paliwo. Podgrzanie jest realizowane dwuetapowo: wstępne podgrzanie paliwa do temperatury około $50^{\circ} \mathrm{C}$ odbywa się przy wykorzystaniu łaźni wodnej, a właściwe podgrzanie do temperatury powyżej $200^{\circ} \mathrm{C}$ następuje w łaźni piaskowej.

Blok chłodzący (3) obniża temperaturę znajdującego się w instalacji badawczej paliwa, po jego wyjściu z układu łaźni piaskowej, poniżej temperatury zapłonu. Chłodzenie realizowane jest dwuetapowo: wstępne chłodzenie paliwa odbywa się poprzez odpowiednio skonstruowaną wężownicę $\mathrm{z}$ rurki stalowej, a właściwe chłodzenie do temperatury poniżej temperatury zapłonu paliwa poprzez termostat chłodzący (chłodnicę).

Blok końcowy (4) pozwala utrzymać wysokie ciśnienie w układzie oraz realizuje zadanie wydzielania produktów rozkładu termicznego paliwa lotniczego.

Zadaniem bloku rejestrującego (5) jest zbieranie sygnałów pomiarowych z czujników umiejscowionych $\mathrm{w}$ pozostałych blokach funkcjonalnych stanowiska badawczego, zapisywanie ich w pamięci oraz wizualizacja. 


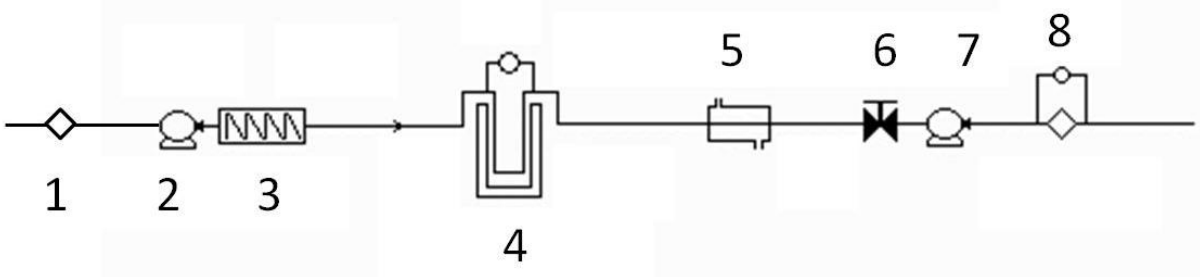

Rys. 2. Schemat funkcjonalny stanowiska badawczego

1. filtr wstępny, 2. pompa, 3. podgrzewacz, 4. taźnia grzewcza, 5. chłodnica, 6. zawór ciśnieniowy, 7. pompa pomocnicza, 8. filtr roboczy

Cały układ badawczy pracuje pod wysokim ciśnieniem, które zapewniają elementy robocze: pompa (2) oraz zawór ciśnieniowy (6).

Badane paliwo jest zasysane z naczynia laboratoryjnego do układu badawczego przez pompę (2). W celu wyeliminowania zanieczyszczeń mogących wpływać na wynik badania, paliwo musi być wstępnie filtrowane, co zapewni filtr wstępny (1). Filtr roboczy (8) pozwoli na wychwytywanie osadów powstałych w paliwie w trakcie badania.

Paliwo tłoczone przez pompę (2) przepływa przez podgrzewacz (3), a następnie przez łaźnię grzewczą (4). Zastosowanie wstępnego podgrzewania jest konieczne z uwagi na fakt, iż paliwo wprowadzane do układu będzie miało temperaturę pokojową (ok. $25^{\circ} \mathrm{C}$ ), natomiast w łaźni grzewczej (4) będzie ogrzewane do temperatury ok. $250-350^{\circ} \mathrm{C}$ (temperatura na zewnątrz przewodów $\mathrm{z}$ paliwem będzie wynosiła ok. $300-400^{\circ} \mathrm{C}$ ), i ważne jest, aby maksymalnie wydłużyć czas, w którym badane paliwo będzie poddane maksymalnej wartości wymuszenia termicznego w łaźni grzewczej.

Łaźnia grzewcza (4) jest najważniejszym elementem układu pomiarowego, zapewniającym odpowiednią wartość temperatury oddziałującej na badane paliwo. Stalowy przewód (sekcja pomiarowa), w którym paliwo przepływa przez łaźnię, jest uformowane w kształt „U”. W tym elemencie zachodzą wszelkie zmiany w paliwie, będące skutkiem oddziaływania wysokich temperatur.

Po wypłynięciu z łaźni grzewczej paliwo przepływa przez obszar chłodzący aż do chłodnicy (5). Zadaniem tego elementu będzie obniżenie temperatury paliwa poniżej temperatury zapłonu (tj. poniżej $\left.40^{\circ} \mathrm{C}\right)$.

Po opuszczeniu części ciśnieniowej stanowiska - po przepłynięciu przez zawór ciśnieniowy (6) - paliwo jest tłoczone za pomocą pompy pomocniczej (7) przez filtr roboczy (8) w celu wydzielenia osadów powstałych w trakcie badania.

Zmiana masy filtra roboczego (8) po zakończeniu badania jest miarą ilości osadów wytworzonych przez paliwo. Drugim parametrem ilościowym jest zawartość węgla i siarki w elemencie roboczym (sekcji pomiarowej w kształcie litery „U”) określana za pomocą dostępnych technik laboratoryjnych. 
Innovative test rig for jet fuels thermal stability testing

Innowacyjne stanowisko badawcze do określania stabilności termicznej...

\section{Mierzone parametry oraz możliwości badawcze}

Poniżej przedstawiono schemat stanowiska $\mathrm{z}$ opisem mierzonych parametrów, a także opisano możliwe tryby wykonywania pomiarów i pozyskiwane $\mathrm{w}$ ten sposób informacje.

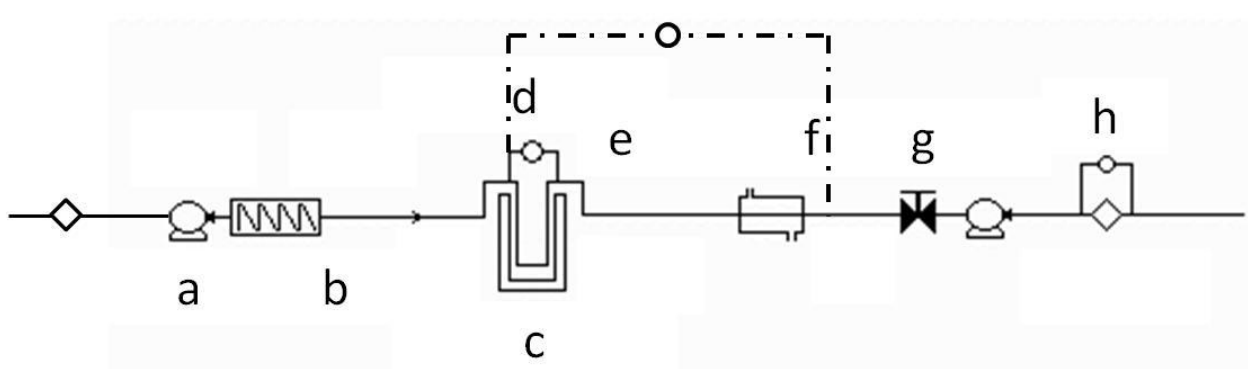

Rys. 3. Koncepcja użytkowa stanowiska badawczego

a) sterowanie natężeniem przeplywu paliwa $w$ uktadzie, b) pomiar temperatury paliwa za podgrzewaczem, c) pomiar temperatury w taźni grzewczej, d) pomiar spadku ciśnienia w sekcji pomiarowej umieszczonej w taźni grzewczej, e) pomiar temperatury paliwa za sekcja pomiarowa, f) pomiar temperatury paliwa za chłodnica, g) sterowanie ciśnieniem $w$ stanowisku, h) ocena procesu termooksydacji paliwa (np. pomiar zmiany masy sqczka, wizualna ocena produktów zgromadzonych na sączku, pomiar spadku ciśnienia na filtrze)

Wartość natężenia przepływu paliwa w układzie pomiarowym jest zadawana poprzez odpowiednie ustawienie parametrów pracy pompy (a) oraz ustawienie wartości ciśnienia utrzymywanego w przewodzie paliwowym za pomocą zaworu (g). Dla paliwa wypływającego z podgrzewacza rejestrowana jest wartość temperatury (c) - w kontroli temperatury paliwa wpływającego do sekcji pomiarowej.

W sekcji pomiarowej rejestrowane są:

- temperatura panująca w łaźni grzewczej (c) pozwalająca na kontrolę wartości narażenia termicznego działającego na przewód $\mathrm{z}$ paliwem umieszczony w łaźni grzewczej;

- spadek ciśnienia wynikający z tworzenia w elemencie zanurzonym w łaźni grzewczej produktów termooksydacji przylegających do ścianek przewodu.

Opisany sposób rejestrowania parametrów umożliwia prowadzenie badań nad mechanizmami i kinetyką procesu degradacji termicznej paliwa lotniczego, a w szczególności:

- obserwację szybkości tworzenia produktów termooksydacji w paliwie lotniczym przy ustalonej wartości wymuszenia termicznego i ustalonych warunkach początkowych (stała objętość badanej próbki, stały czas badania, zadana stała temperatura łaźni grzewczej, ustalona stała wartość natężenia przepływu, ustalone ciśnienie w układzie pomiarowym); 
- obserwację wpływu wartości wymuszenia termicznego na proces termooksydacji paliwa lotniczego (stała objętość badanej próbki, stały czas badania, zmienna temperatura łaźni grzewczej, ustalona stała wartość natężenia przepływu, ustalone ciśnienie w układzie pomiarowym);

- obserwację wpływu czasu działania ustalonego wymuszenia termicznego na proces termooksydacji paliwa lotniczego (stała objętość badanej próbki, zmienny czas badania regulowany poprzez zmienną wartość natężenia przepływu, stała temperatura łaźni grzewczej, ustalone ciśnienie w układzie pomiarowym).

Ogólny widok zbudowanego w Instytucie Technicznym Wojsk Lotniczych stanowiska, z podziałem na bloki pomiarowe, przedstawiono poniżej na rys. 4 .

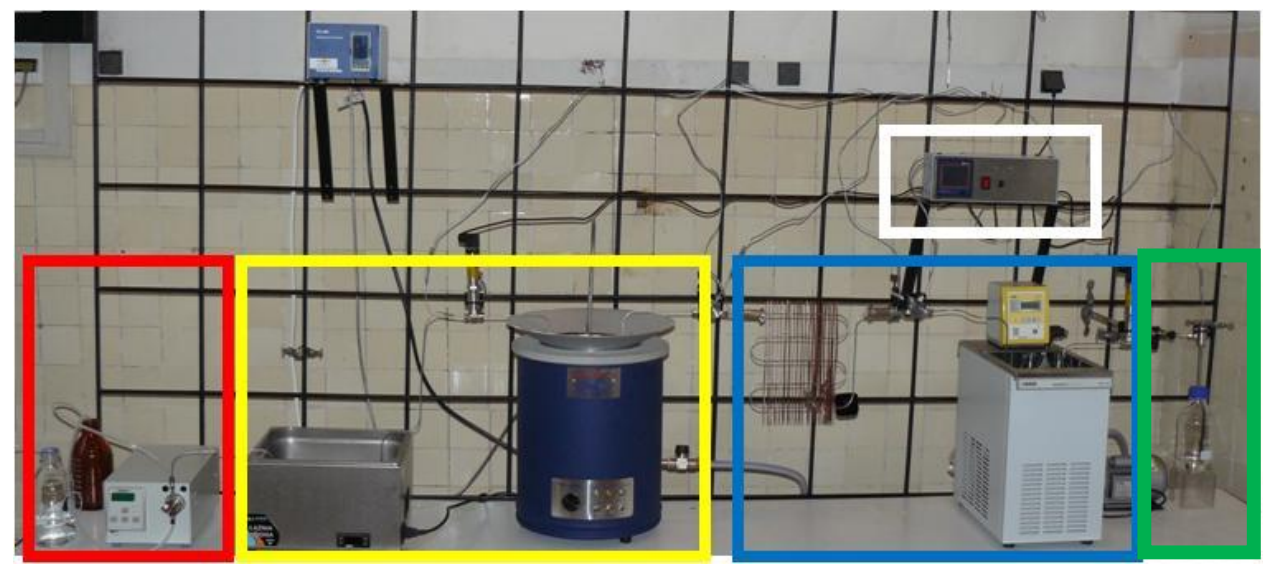

Rys. 4. Widok ogólny stanowiska badawczego z podziatem na bloki robocze: Blok filtracyjno-tloczacy - ramka czerwona; Blok grzewczy - ramka żólta; Blok chłodzacy - ramka niebieska; Blok końcowy - ramka zielona; Blok rejestrujacy ramka biata.

\section{Podsumowanie}

Opracowane w Instytucie Technicznym Wojsk Lotniczych - w ramach realizacji projektu badawczego finansowanego przez Narodowe Centrum Nauki - stanowisko badawcze stanowi rozwiązanie innowacyjne i unikalne w skali europejskiej. Umożliwia prowadzenie badań nad procesami degradacji termicznej paliw lotniczych zachodzącymi w szerokim zakresie temperatur $\left(\right.$ do $\left.500^{\circ} \mathrm{C}\right)$ oraz ciśnień (do $20 \mathrm{MPa}$ ). Możliwość sterowania działającymi na paliwo lotnicze wymuszeniami pozwala na symulację warunków pracy różnych układów paliwowych, prowadzenie zaawansowanych badań nad przebiegiem procesów termicznych zachodzących w paliwie, a także prac nad dodatkami oraz technologiami poprawy bardzo istotnego $\mathrm{z}$ punktu widzenia bezpieczeństwa eksploatacji statków powietrznych parametru, jakim jest stabilność termooksydacyjna paliw lotniczych. 
Innovative test rig for jet fuels thermal stability testing

Innowacyjne stanowisko badawcze do określania stabilności termicznej...

\section{Literatura}

[1] S.D. Anderson, T. Edwards, W.E. Harrison "U.S. Air Force Improved JP-8 Development Program - An Overview", 2nd International Symposium on Aviation Turbine Fuel Specifications, 11-13 May 1993

[2] G. Datschefski, "Critical review of the JFTOT", Aviation fuel: thermal stability requirements, ASTM STP 1138, P. W. Kirklin, P. David, Eds., American Society for Testing and Materials, Philadelphia, 1992

[3] R. E. Morris, J. M. Hughes, J. E. Colbert, "The Impact of Copper on the Liquid-Phase Oxidation ofJet Fuel for Advanced Aircraft", Energy \& Fuels, 2004, 18, s. 490-496

[4] J. S. Ervin, T. A. Ward, T. F. Williams, J. Bento, "Surface Deposition within Treated and Untreated Stainless Steel Tubes Resulting from ThermalOxidative and Pyrolytic Degradation of Jet Fuel," Energy \& Fuels, vol. 17, s. 577-586, May 2003

[5] T. Edwards, "Cracking and Deposition Behaviour of Supercritical Hydrocarbon Aviation Fuels," Combustion Science and Technology, vol. 178, s. 307-334, January 2006

[6] ASTM D3241 "Standard Test Method for Thermal Oxidation Stability of Aviation Turbine Fuels", www.astm.org

[7] Aviation Fuels Quality Requirements for Jointly Operated Systems, www.jigonline.com

[8] ASTM D1655 "Standard Specification for Aviation Turbine Fuels", www.astm.org

[9] ASTM D7566 "Standard Specification for Aviation Turbine Fuel Containing Synthesized Hydrocarbons", www.astm.org

The project has been funded by National Science Centre granted with decision no. DEC-2011/01/D/ST8/06567.

Projekt zostal sfinansowany ze środków Narodowego Centrum Nauki przyznanych na podstawie decyzji numer DEC-2011/01/D/ST8/06567.

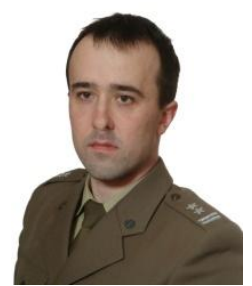

Dr inz. Jaroslaw Sarnecki jest absolwentem Wojskowej Akademii Technicznej. Od 1999 r. pracuje w Instytucie Technicznym Wojsk Lotniczych (1999-2002 - Zakład Diagnostyki Techniki lotniczej, 2002-2006 - Zakład Silników Lotniczych, od 2006 r. - Zaktad Materiałów Pędnych i Smarów), a od 2007 r. petni funkcję kierownika Zakładu Materiałów Pędnych i Smarów. 